\title{
Maximum ST Deviation
}

National Cancer Institute

\section{Source}

National Cancer Institute. Maximum ST Deviation. NCI Thesaurus. Code C62157.

The maximum deviation (distance from baseline, positive or negative, usually measured

in $\mathrm{mm}$ ) of the ST segment, obtained from a set of measurements of the deviation of the ST segment. 